\title{
Familiarity and Usage of Social Media Technology: An Exploratory Study of Teachers in Ghana
}

\author{
Yeboah Solomon Tawiah, Horsu Emmanuel Nondzor \\ School of Business and Management Studies, Department of Marketing, Cape Coast Polytechnic, Cape Coast, Ghana
}

Email address:

soloty2002@gmail.com (S. T. Yeboah), rtchorsu8@gmail.com (E. N. Horsu)

\section{To cite this article:}

Yeboah Solomon Tawiah, Horsu Emmanuel Nondzor. Familiarity and Usage of Social Media Technology: An Exploratory Study of Teachers in Ghana. Science Journal of Business and Management. Vol. 3, No. 2, 2015, pp. 50-59. doi: 10.11648/j.sjbm.20150302.11

\begin{abstract}
The growth of social media sites has been a phenomenon in the last few years. However, not much is known about how teachers have embraced the technology as the phenomenon is virtually unexplored in the extant literature in Ghana. The research therefore explored this issue by examining familiarity and usage of social media technology among teachers in Ghana. Teachers in Ghana were randomly selected from ten schools and pretested questionnaires were randomly administered to them. The empirical evidence suggested that majority of the teachers were familiar with social media technology and are using one or more of these social media sites. They access the social media sites through their smart phone as a preferred mode of internet device. The most familiar social media sites which emerged were Facebook [99\%], Wiki [99\%], followed by YouTube [98.5], Instagram [91.4\%], Web-blogs [87.8\%], Slideshare [84\%] and LinkedIn [76.1\%]. However, Facebook and YouTube are the most used media sites among the teachers with $96.4 \%$ and $93.9 \%$ respectively. They spend over 22 hours a week on the sites for several purposes including personal and professional development. In spite of the increasing usage, over $76 \%$ of the teachers have not integrated it for instructional purpose in the classroom although few of them occasionally share academic and useful information to their students. Some of the reasons which were given for not using the tools for instructional purpose include, fear of privacy violation, not part of curriculum, cyber abuse, distraction of students' studies and infrastructural problems among others.
\end{abstract}

Keywords: Familiarity, Usage, Exploratory, Technology, Teachers, Social Media, Tools, Web 2.0.

\section{Introduction}

The use of social media has gained significant dominance and popularity in recent technological waves. People all over the world have embraced social media technology in one way or the other $[1 ; 2 ; 3]$. Various researchers have reported on the familiarity and the use of social media for diverse purposes $[4 ; 5 ; 6 ; 7]$. In one of the most effective articles on social media in teaching, learning and sharing, [8] discovered that faculty are significantly accepting and using social media technologies. Practically all higher education teaching faculties are very much familiar with the major social media sites; more than three-quarters visited social media sites for their personal use; and nearly one-half posted content. Even more impressive is their rate of adoption of social media in their professional lives: over $90 \%$ of all faculties are using social media in courses they're teaching or for their professional careers outside the classroom.

Social media as a term has been defined by [9] as the collections of Internet websites, services, and practices that support collaboration, community building, participation, and sharing. These technologies include blogs, wikis, media (audio, photo, video, text) sharing tools, networking platforms (including Facebook), and virtual worlds $[10 ; 11 ; 12]$.

The importance of social media in today's world cannot be overemphasized as it permeates every facet of life. Researchers $[13 ; 14]$ have espoused the benefits social media applications bring: social media enriches the learning experience by allowing students and instructors to exchange ideas; foster collaboration and discussion; and engage and interact using such emerging social platforms. It is an effective way to increase student engagement and build communication skills by allowing students to feel more comfortable expressing themselves in a less intimidating environment. It can also improve communication between students and instructors, while the latter can answer students' 
questions, post homework assignments and lesson plans, send messages and updates, schedule or announce upcoming events, and share Web sites, multimedia contents and more importantly, students use social networking sites to find employment by establishing a professional Web presence, posting a resume, and researching potential employers. [4; 6] have also reported on their global acceptability and usage: as of July 2011, Facebook users have exceeded 800 million, LinkedIn had over 100 million members, Twitter had over 177 million tweets per day, and YouTube reached three billion views per day. Their obvious importance and relevance have led to its embracement in day-to-day interactions $[4 ; 5 ; 7]$.

\subsection{Teachers and Social Media}

An explosive number of people across the world have been exposed to the social media and social network tools as reported by $[15 ; 14 ; 5]$ in their findings. Teachers and students at both basic and higher education faculties are familiar with the major social media sites. However, there are big differences among the patterns of use from one social media site to another. In America for example, Facebook is the most visited site for personal use, by a large margin of teachers, thus, the one with the highest rate of postings. YouTube is the second most visited, but posting rates are low. YouTube and Facebook are also the most frequently cited when faculty report on their uses of social media in support of their professional careers [16]. Teachers in institutions have been reported to use the sites for various purposes including supporting their professional career and classroom activities. Moreover, there is a similar evidence for the level of integration of social media into course assignments. Over $40 \%$ of faculties have assigned students to read or view social media as part of course assignments, and $20 \%$ have assigned students to comment on or post to social media sites. In total, $80 \%$ of faculties are reported to be using social media for some aspect of a course they are teaching [16].

\subsection{Social Media and Privacy}

As the familiarity and usage increases, there are concerns of whether users' privacy is safeguarded $[6,17]$. A privacy policy is simply a legal document that discloses how customer data is managed and used [17]. Most consumers have been reported clueless of what constitute privacy statement and as such reveal certain sensitive information including personal identities like real names, date of birth, email addresses, cell phone numbers, their photos, profession, work places, financial commitments, relationship status as well as automatically activating their location status about themselves on these social media sites as the sites are designed to encourage sharing of such information without analyzing individual personal safety [18]. In spite of this, some few users take an array of steps to restrict and prune their profiles, and their patterns of reputation management on social media vary greatly according to their gender and network size [16]. In spite of these concerns, users believe that social media sites offer valuable tools for teachers, and a majority report that social media sites can be valuable tools for collaborative learning, personal and professional development [8]. However, the percentage of faculty teachers and students using them for academic practice is still low [19; 5; 4]. In Ghana especially, not enough literature works have been reported on the familiarity and nature of usage among teachers. Hence, it is difficult to categorically state exactly the level of familiarity and how the tools are used among teachers. Those studies that have emerged in Ghana, to the best of the researchers knowledge, have only sought to explore and concentrate on the impact, and usage among students in general etc. $[20 ; 6]$. It is therefore imperative to explore about the familiarity of the social media technology among the teachers and how it is being used in their day-totoday activities. Specifically, the study looked at the following areas; the level of computer literacy among the respondents (i.e. to ascertain whether they possess the requisite computer knowledge to enable them use the social media tools); to examine their level of familiarity of the tool; to examine their perceived level of proficiency and weekly time commitments; and finally to examine the nature of usage, as in personal or professional interactions? The study further examined their opinions towards the social media technology.

\section{The Methods}

A cross-sectional approach was undertaken from May to December, 2014 to conduct an exploratory study on ten different schools in Cape Coast, Ghana. A modified survey questionnaire was designed to gather data from teachers with respect to how they use the tools in their day-to-day endeavors. The study used both primary and secondary data. The primary data was gathered using pretested questionnaire designed to gather the usage pattern of the sample. For the secondary data, peer reviewed journals, articles and several internet data were used. The schools were stratified into second cycle and tertiary institutions and random selection was used to select respondents. Overall 250 questionnaires were distributed, out of which 200 were retrieved and used for the analysis. The study made use of a descriptive statistical tool to evaluate the facts gathered. Both Excel and Statistical Package for Social Sciences (SPSS) were used to code and analyze the responses and results were presented using tables, pie and bar charts, for easy interpretation.

\section{Results}

Table 1 reflects the respondents' profile of the teachers in terms of gender, teaching experience, and the sector of teaching. Accordingly, $73 \%$ are made of male whilst $27 \%$ are females. Overall, $72.5 \%$ of the teachers have up to ten years, and $20.5 \%$ have over 11 years and above. In addition, $55 \%$ of the respondents were made up of tertiary teachers and similarly, the senior high school counterparts are made up of $45 \%$ of the total sample. 


\subsection{Respondents Profile}

\subsection{Level of Computer Literacy among Respondents}

Table 1. Respondents Profile.

\begin{tabular}{llll}
\hline & & Frequency & Percentage \\
\hline \multirow{2}{*}{ Gender } & Male & 146 & 73 \\
& Female & 54 & 27 \\
Teaching & $0-10$ years & 145 & 72.5 \\
Experience & 11 -20 years and above & 41 & 20.5 \\
Teaching & Senior High School (SHS) & 90 & 45 \\
Sector & Tertiary & 110 & 55 \\
\hline
\end{tabular}

Source: Field data [2014]

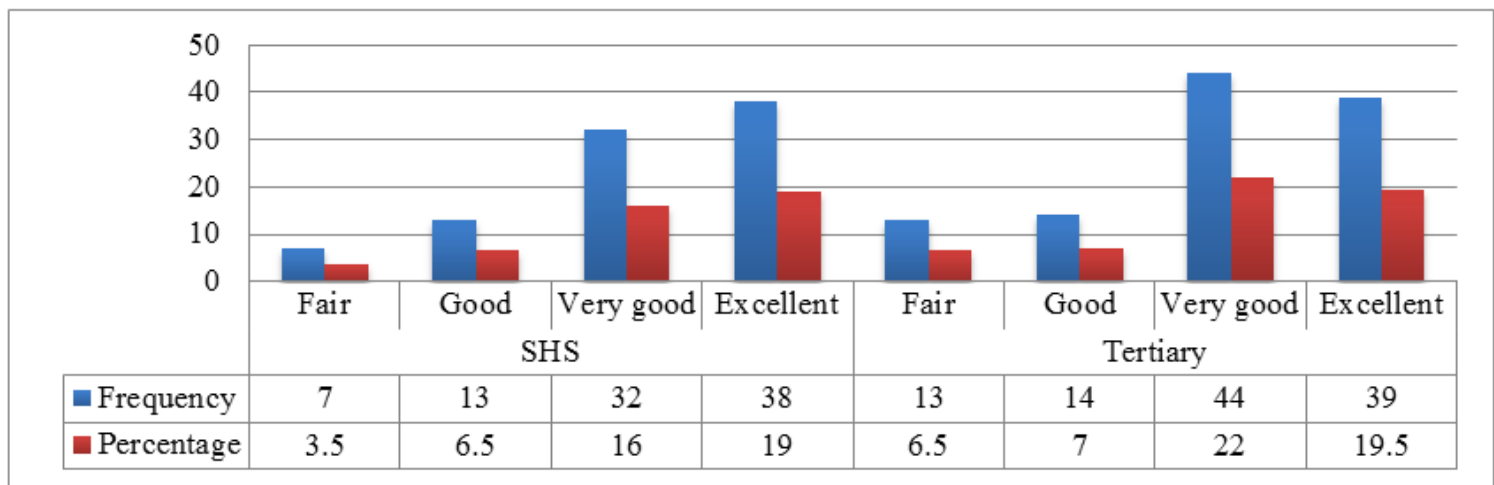

Figure 1. Level of computer literacy among respondents

Source: Field Data [2014]

We wanted to know the respondents' ability to use computer and its related devices like tablets and usage of social media sites for that purpose etc. Therefore, respondents were asked to rate their proficiency in computing. Overall, $38.5 \%$ of both teachers in tertiary and SHS have excellent level of computer literacy, and just $10 \%$ of teachers of both sectors indicated they have just fair level of computer literacy. Respondents' level of computing is well grounded with a total of $77 \%$ having excellent level of computer literacy.

\subsection{Do You Have Access to each of the following Computer Devices?}

Table 2. Accessibility to computer devices

\begin{tabular}{|c|c|c|c|}
\hline \multirow{2}{*}{ Institution } & \multirow{2}{*}{ Questions/Statement } & \multicolumn{2}{|c|}{ Frequency/Percentage } \\
\hline & & Yes & No \\
\hline \multirow[t]{5}{*}{ SHS } & Accessibility to desktop computer with internet connectivity & $30(33.3)$ & $60(66.7)$ \\
\hline & Laptop with internet connectivity (Wireless, Modem etc.) & $65(72.2)$ & $25(27.8)$ \\
\hline & Tablet device (for example: iPad) with internet connectivity & $10(11.1)$ & $80(88.9)$ \\
\hline & Mobile device (cell phone) with internet connectivity & $85(94.4)$ & $5(5.6)$ \\
\hline & Accessibility to computer lab & $80(88.9)$ & $10(11.1)$ \\
\hline \multirow[t]{5}{*}{ Tertiary } & Accessibility to desktop computer with internet connectivity & $99(90)$ & $11(10)$ \\
\hline & Laptop with internet connectivity (Wireless, Modem etc.) & $98(89.1)$ & 12(10.9) \\
\hline & Tablet device (for example: iPad) with internet connectivity & $71(64.5)$ & $39(35.5)$ \\
\hline & Mobile device (cell phone) with internet connectivity & $105(95.5)$ & $5(4.5)$ \\
\hline & Accessibility to computer lab & $110(100)$ & $0(0)$ \\
\hline
\end{tabular}

Source: Field Data [2014]

To obtain information on whether the respondents' have accessibility to the internet and social media sites and the kind of computer device, they were asked to indicate against a set of statement made at Table 2. Accessibility to desktop computer of the tertiary teachers recorded a higher percentage of $99 \%$ than SHS teachers which recorded just $33.3 \%$. Similarly, laptop with internet connectivity was also higher than SHS recording $98 \%$ and $72.2 \%$ respectively.
Mobile devices also scored higher percentages of $95.5 \%$ and $94.4 \%$ with tertiary and SHS respectively. Tablet accessibility was recorded with the tertiary as $64.5 \%$ whiles that of the SHS recorded $11.1 \%$. However, computer labs accessibility is quite high with both SHS and the tertiary with $88.9 \%$ and $100 \%$ respectively. Respondents' access to computer devices is good. 


\subsection{Familiarity and Usage of Social Media Technology}

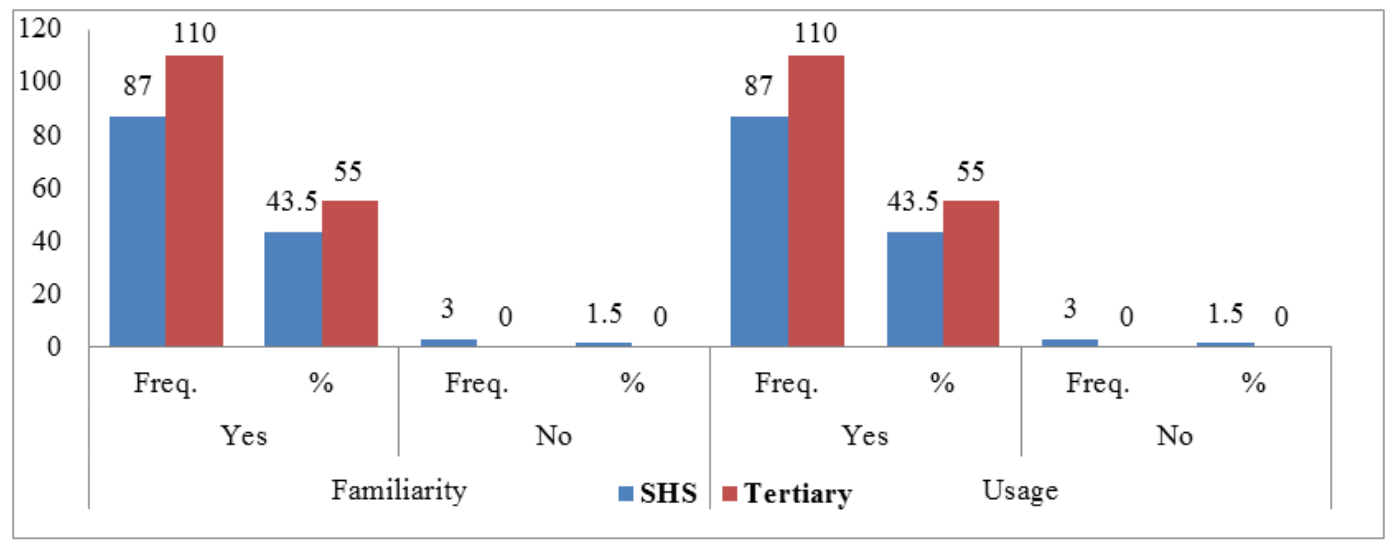

Figure 2. Familiarity and Usage of Social Media Technology.

Source: Field Data [2014]

Social media technology has gained popularity among both SHS and tertiary teachers. The study overwhelmingly measured overall responses of $100 \%$ (i.e. $55 \%$ of the total sample size) of the tertiary teachers and that of SHS similarly recording $96.7 \%$ (i.e. $43.5 \%$ ). Regarding the usage, the same percentage of $55 \%$ of the tertiary teachers was recorded of the total sample size. Similarly, SHS teachers recorded $43.5 \%$ of the total sample size. Just $1.5 \%$ is not using any social media sites as they are unfamiliar with social media technology.

\subsection{Perceived Level of Proficiency}

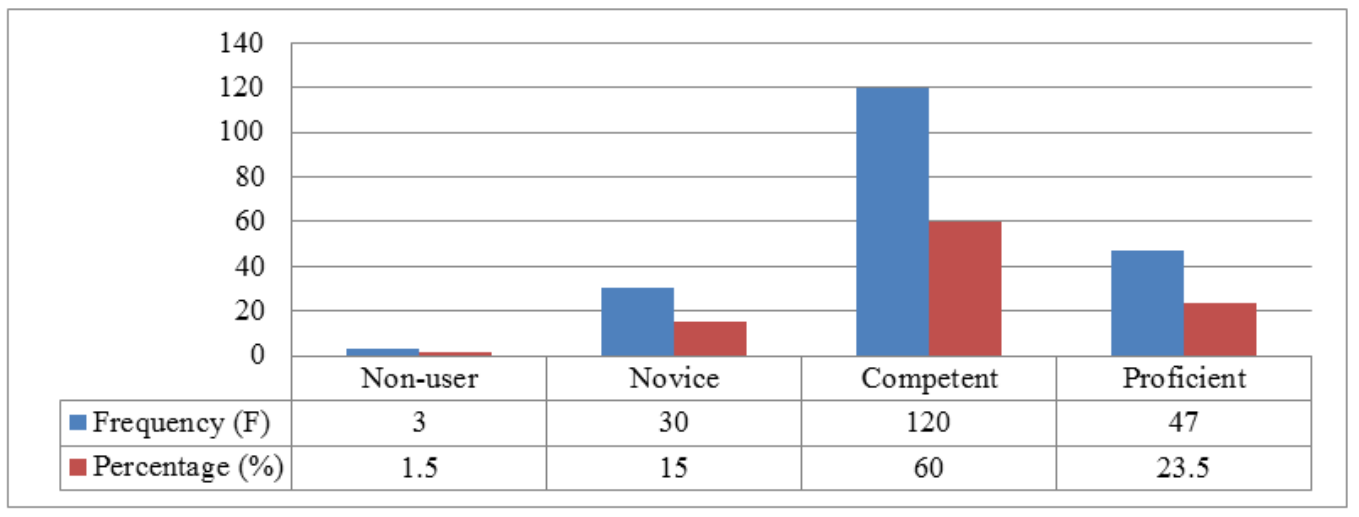

Notes: Non-user: "Not familiar of it or don't use it"; Novice: "Have used it once or twice"; Competent: "Has an account and mostly use it to read content" Proficient: "Frequently use the application to both read content and contribute content;

Source: Field data [2014]

Figure 3. Perceived Level of Proficiency

Respondents were asked to rate themselves on their skills on using social media tools according to their perceived levels of proficiency as in 'non-user', 'novice', 'competent' or 'proficient' in the context of general practice for everyday use in several dimension. Overall, $60 \%$ of the teachers are competent enough to use the tools in their everyday practice. Just $1.5 \%$ and $15 \%$ are non-users and novice respectively.

\subsection{How do You Mostly Access Social Media Sites}

Figure 4 reflects respondents' preferred internet device to access social media sites. Respondents were restricted to just one selection of most preferred media for accessing the social media sites. Obviously, smart phones emerged as mostly used with $56 \%$ and interestingly PC was the least choice (8\%).

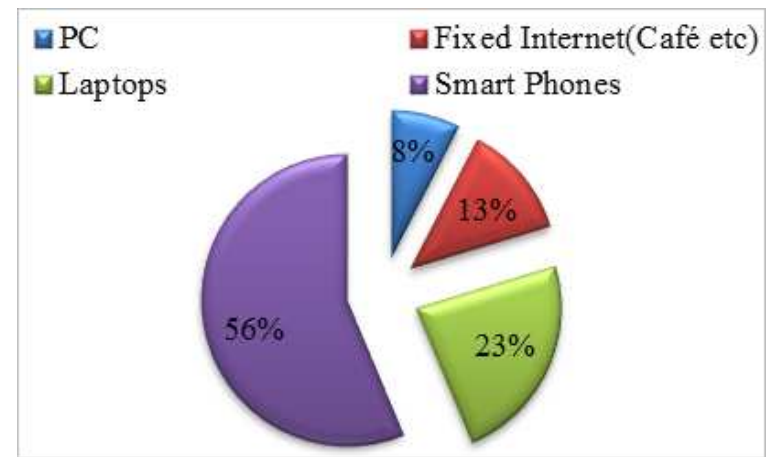

Figure 4. Internet device used in accessing social media sites.

Source: Field Data [2014] 


\subsection{Familiarity and Usage of Selected Social Media Sites}

Table 3. Familiarity and Usage of Selected Social Media Sites

\begin{tabular}{|c|c|c|c|c|}
\hline Familiarity & Frequency & Percentage & Frequency & Percentage \\
\hline Media Site & Yes & & No & \\
\hline Facebook & 195 & 99.0 & 2 & 1.0 \\
\hline LinkedIn & 150 & 76.1 & 47 & 23.9 \\
\hline Twitter & 135 & 68.5 & 62 & 31.5 \\
\hline Pinterest & 137 & 69.5 & 60 & 30.5 \\
\hline MySpace & 56 & 28.4 & 141 & 71.6 \\
\hline $\mathrm{Hi} 5$ & 115 & 58.4 & 82 & 41.6 \\
\hline Slideshare & 167 & 84.8 & 30 & 15.2 \\
\hline Wikis & 195 & 99.0 & 2 & 1.0 \\
\hline Flicker & 25 & 12.7 & 172 & 87.3 \\
\hline YouTube & 194 & 98.5 & 3 & 1.5 \\
\hline Blogs & 173 & 87.8 & 24 & 12.2 \\
\hline $\begin{array}{l}\text { Instagram } \\
\text { Usage }\end{array}$ & 180 & 91.4 & 17 & 8.6 \\
\hline Facebook & 190 & 96.4 & 7 & 3.6 \\
\hline LinkedIn & 135 & 68.5 & 62 & 31.5 \\
\hline Twitter & 100 & 50.8 & 97 & 49.2 \\
\hline Pinterest & 59 & 29.9 & 138 & 70.1 \\
\hline MySpace & 25 & 12.7 & 172 & 87.3 \\
\hline $\mathrm{Hi} 5$ & 19 & 9.6 & 178 & 90.4 \\
\hline Slideshare & 111 & 56.3 & 86 & 43.7 \\
\hline Wikis & 183 & 92.9 & 14 & 7.1 \\
\hline Flicker & 10 & 5.1 & 187 & 94.9 \\
\hline YouTube & 185 & 93.9 & 12 & 6.1 \\
\hline $\mathrm{B} \log s$ & 170 & 86.3 & 27 & 13.7 \\
\hline Instagram & 165 & 83.8 & 32 & 16.2 \\
\hline
\end{tabular}

Field Data [2014]
Moreover, respondents were given a list of some social media sites to indicate their familiarity and usage of those sites at Table 3. The results recorded Facebook and Wiki as most popular sites among respondents [99\%], followed by YouTube [98.5] and Instagram [91.4\%] and web-blogs [87.8\%] respectively. Similarly, the next popular social media sites among respondents are Flicker [87.3\%], MySpace [71.6\%] and Hi5 [41.6] respectively.

Similarly, respondents were asked to indicate their usage of same social media sites listed. Again Facebook featured the most used with $96.4 \%$, followed by YouTube [93.9\%], Wiki [92.9\%], Blogs [86.3\%], LinkedIn [68.5\%], Slideshare [56.3\%], and Twitter [50.8\%]. Again, Flicker [5.1\%], Hi5 [9.6\%] MySpace [12.7\%] emerged the least used social media network among all the listed sites.

\subsection{Perceived Level of Confidence in Using Social Media Tools}

Table 4. Perceived Level of Confidence in Using Social Media Tools.

\begin{tabular}{|c|c|c|c|c|}
\hline \multirow{2}{*}{ Variables } & Not at all confident & A little confident & Confident & Very Confident \\
\hline & $\mathbf{N}(\%)$ & $\mathbf{N}(\%)$ & $\mathbf{N}(\%)$ & $\mathbf{N}(\%)$ \\
\hline Producing/editing online document (e.g. using Googledocs etc.) & $86(43.7)$ & $30(15.2)$ & $50(25.4)$ & $31(15.7)$ \\
\hline Communicating with others using email or instant messaging tools & $1(0.5)$ & $29(14.7)$ & $58(29.4)$ & $109(55.3)$ \\
\hline $\begin{array}{l}\text { Communicating with others using social networking tools, such as } \\
\text { Facebook, WhatsApp }\end{array}$ & $3(1.5)$ & $8(4.1)$ & $144(73.1)$ & $42(21.3)$ \\
\hline Communicating online using web conferencing tools, such as Skype & $10(5.1)$ & $15(7.6)$ & $127(64.5)$ & $45(22.8)$ \\
\hline Creating online courses (e.g. using Blackboard or Moodle) & 22(11.6) & $76(38.6)$ & $48(24.4)$ & $51(25.9)$ \\
\hline $\begin{array}{l}\text { Capturing, editing and sharing digital photos or graphics online (e.g. via } \\
\text { Flickr) }\end{array}$ & $16(8.1)$ & $18(9.1)$ & $105(53.3)$ & $58(29.4)$ \\
\hline Capturing, editing and sharing digital videos online (e.g. via YouTube) & $20(10.2)$ & 26(13.2) & $102(51.8)$ & $49(24.9)$ \\
\hline Delivering a course to learners online & $100(50.8)$ & $20(10.2)$ & $16(8.1)$ & $61(31.0)$ \\
\hline
\end{tabular}

Source: Field Data [2014]

The overall number of respondents who are not confident in using the tools, according to Table 4 , to produce and edit online documents is almost half of the sample size [43.7\%]. However, $15.2 \%$ are a little confident, and $25.4 \%$ are confident whilst similarly, 15.7 are very confident to the same statement. Moreover, $50 \%$ of the respondents indicated not confident in using social media in delivering a course online to learners but interestingly, 31\% similarly indicated they are very confident to the same statement. Interesting $55.3 \%$ is very confident communicating with others using email or instant messaging tools. Besides, overwhelming percentage of $73.1 \%$ is confident using the tools to communicate via media such as Facebook and WhatsApp confirming the increasing ascendancy of Facebook as most popular site and usage among respondents as reported by Table 3. Again, respondents are confident in capturing, editing, and sharing digital photos online recording 53.3\%. Perhaps this is due to the fact that most respondents are more attached to smart phone devices [See Figure-4] which come in handy with digital camera tools. 


\subsection{Do You Use Social Media for Instructional Purpose}

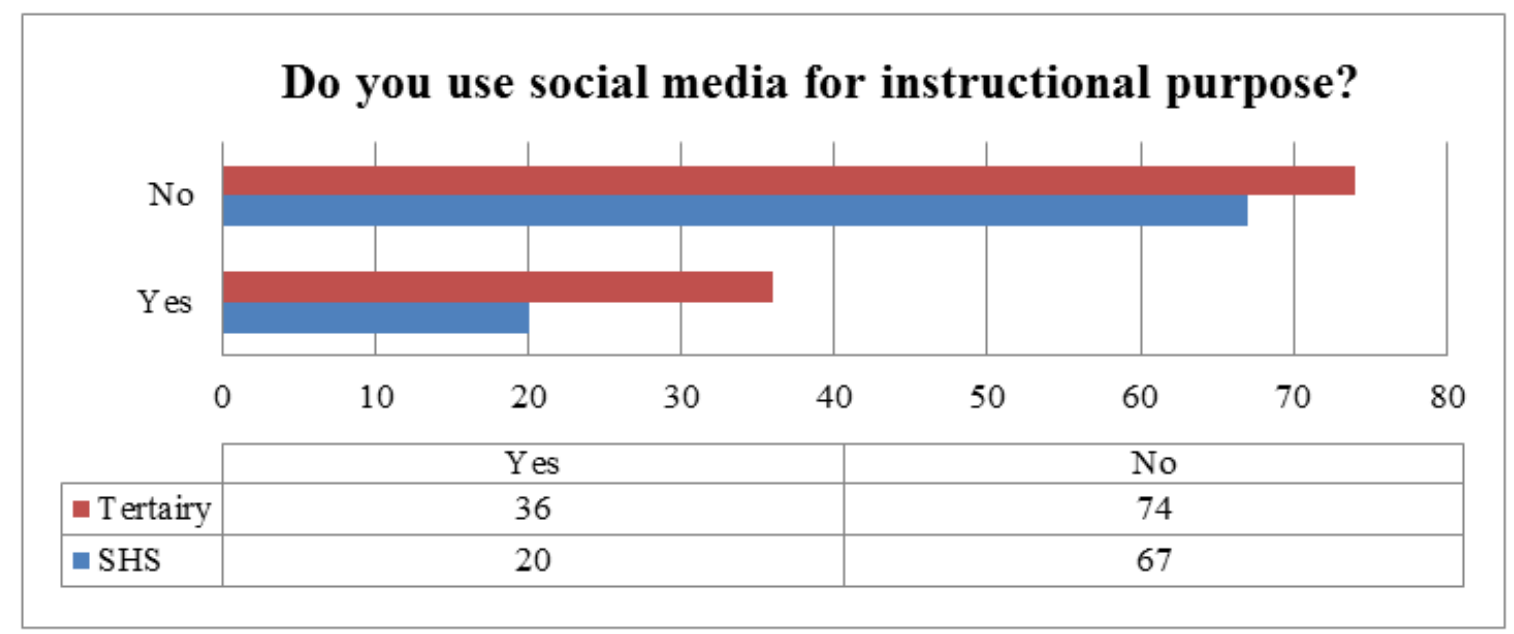

Figure 5. Instructional usage of social media in the classroom.

Source: Field Data [2014]

Figure 5 reflects the number of teachers who use social media for classroom and instructional purpose. Obviously, just $36(18.3 \%)$ of the total sample size of the Tertiary teachers confirmed using it for instructional purpose and majority of $74(37.6 \%)$ are not using it for instructional practice. Similarly, 20(10.2\%) of the SHS teachers indicated using the tools for such reasons and again majority of them,
$67(34.0 \%)$ do not use it for instructional purpose in the classroom. Overall, a significant majority of $141(71.6 \%)$ do not use social media technologies for instructional/classroom practices.

\subsection{Reasons for not Using Social Media for Instructional Purpose}

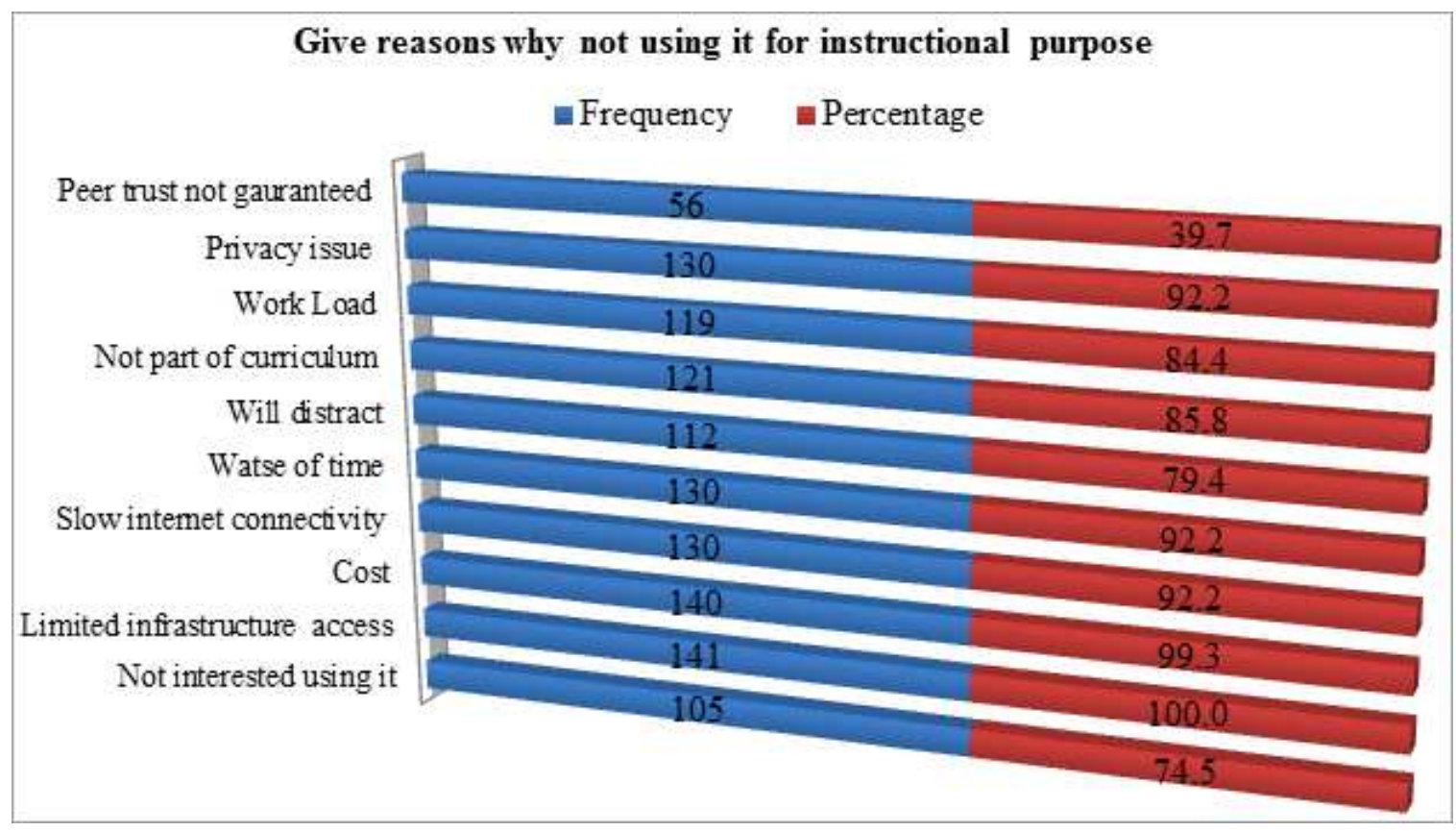

Figure 6. Reasons for not using social media for instructional practice.

Source: Field Data. Percentage calculation was based on the number who do not use social media for instructional practice as obtained from Figure 4, (N=141)

The respondents were allowed to specify why they don't use social media for classroom practice. From Figure 6, some of the issues specified included, limited infrastructure (100\%), cost $(99.3 \%)$, and privacy, time wasting, slow internet connectivity (all recorded 92.2\%), not part of curriculum
(85.8\%), and workload (84.4\%) respectively emerged as top reasons for not using social media for instructional practice by the teachers. 


\subsection{Weekly Time Commitment to Social Media}

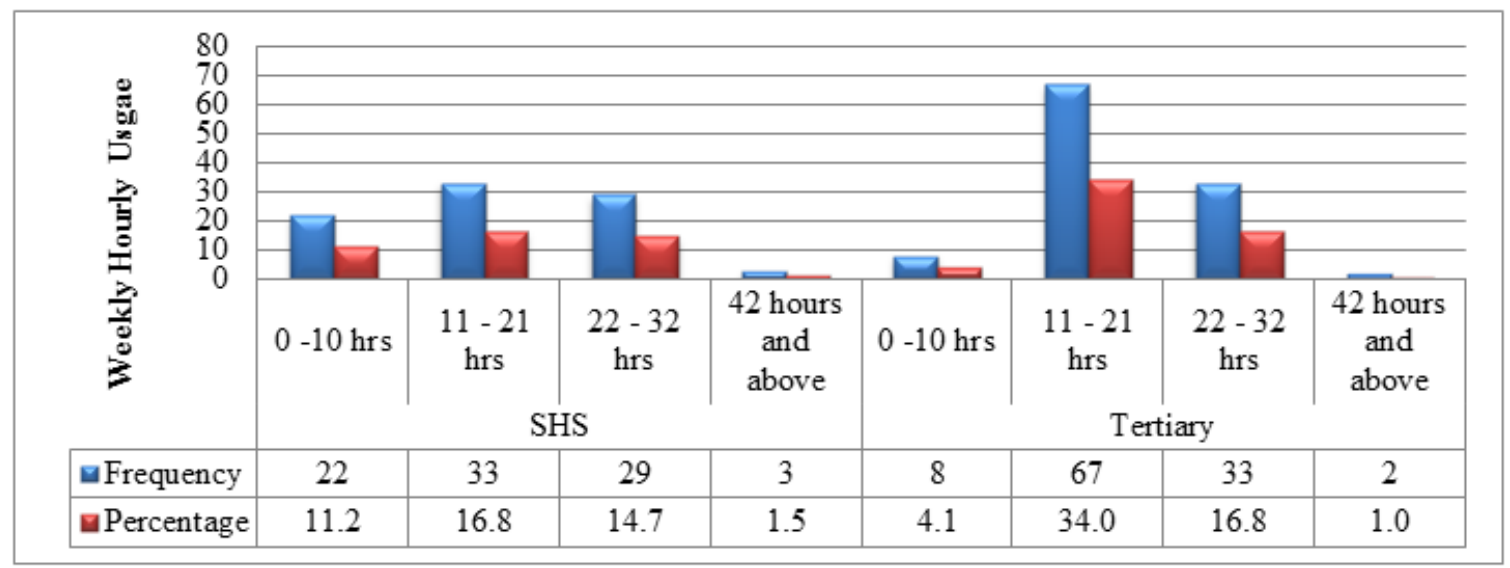

Figure 7. Weekly Time commitment to Social Media.

Source: Field Data[2014]

Figure 7 obtained weekly hourly usage between the two sectors of the teachers. It was discovered that, tertiary teachers spend more hours on social media with $34 \%$ of them spending 11-21 hours per week. However, the same hours of 11-21 per week was similarly recorded by $16.8 \%$ of SHS teachers. Moreover, for 22-32hours per week, 33\% of the tertiary teachers was recorded whilst $29 \%$ of the SHS teachers were recorded spending the same hours of 2232 hours per week lower than the tertiary teachers. Regading $0-10$ hours, $11.2 \%$ of the SHS teachers were recorded whilst the tertiary teachers registered just $4.1 \%$ for the same hours per week.

\subsection{Purpose of Social Media Usage}

Table 5a. Purpose of Social Media Usage.

\begin{tabular}{|c|c|c|c|c|}
\hline \multirow{2}{*}{ Purpose of usage } & \multicolumn{2}{|l|}{ Yes } & \multicolumn{2}{|l|}{ No } \\
\hline & Frequency & Percentage & Frequency & Percentages \\
\hline Use as discussion forums & 80 & 40.6 & 117 & 59.4 \\
\hline For real time chat & 196 & 99.5 & 1 & 0.5 \\
\hline For video conferencing & 80 & 40.6 & 117 & 59.4 \\
\hline Interact with students & 175 & 88.8 & 22 & 11.2 \\
\hline Share links and organise information & 195 & 99.0 & 2 & 1.0 \\
\hline Interact in an online classroom & 65 & 33.0 & 132 & 67.0 \\
\hline To access resources to enhance teaching and learning & 183 & 92.9 & 14 & 7.1 \\
\hline To share images online & 189 & 95.9 & 8 & 4.1 \\
\hline For Publishing and Blogging & 75 & 38.1 & 122 & 61.9 \\
\hline For research purposes & 195 & 99.0 & 2 & 1.0 \\
\hline Delivers a course online & 3 & 1.5 & 194 & 98.5 \\
\hline Engage in online courses & 70 & 35.5 & 127 & 64.5 \\
\hline
\end{tabular}

Notes: Percentage analysis was based on the number (197) familiar with social media sites, according to Figure 2.

Source: Field Data [2014]

Table 5 reflects on how both sectors of teachers generally use social media sites. They were asked to indicate by either yes or no to a set of statements regarding their usage pattern. Some of the keys findings include the use of the tools as a discussion forum with $40.6 \%$ whiles $59.4 \%$ responded negatively. Overall, $50.8 \%$ of the teachers used the tool for a real time chat such as instant messaging as against $0.5 \%$ who does not use it for such purpose. Moreover, video conferencing recorded $40.6 \%$ 'Yeses' with 'No' responses of $59.4 \%$. However, significant number of the teachers use the media to interact with students with $88.8 \%$ and contrariwise, just $11.2 \%$ do not use it for that purpose. Similarly, $99.0 \%$ use the sites to share links and organise information registered whilst just 1\% says No to the same statement. An online classroom interaction: $33.0 \%$ (Yes), and $67 \%$ (No); Sharing instructional videos: $88.8 \%$ (Yes) and $11.2 \%$ (No); Access resources to enhance teaching and learning: $92.9 \%$ (Yes) and 7.1\% (No); Sharing Images online: 95.9\% (Yes) and 4.1\% (No); Publishing and Blogging: 38.1\% (Yes) and 61.9\%; Research purposes: $99.0 \%$ (Yes) and (1.0\%); Deliver a course online: just 3\% (Yes) and as many as $98.5 \%$ (No); and finally $70 \%$ of the teachers engage in online courses through social media sites with $64.5 \%$ saying no to same question. 
Table 5b. Other purposes of usage.

\begin{tabular}{lll}
\hline What other reasons do you use social media sites for? & Frequency & Percentages \\
\hline To get news, and information from various sources & 197 & 100 \\
For fun / Entertainment & 196 & 99.5 \\
To share opinion on different issues/topics & 170 & 86.3 \\
To contribute to community/activist/political matters & 150 & 76.1 \\
For professional purposes/job finding & 185 & 93.9 \\
To connect with family, friends and like minded & 195 & 99.0 \\
\hline
\end{tabular}

Source: Field Data [2014]

Asked to specify how they use social media sites differently apart from statements at Table 5a, some of the reasons the teachers specified involve purposes such as getting news and information from various sources (100\%); for fun and entertainment $(99.5 \%)$; sharing opinions on topical issues $(86.3 \%)$; contribute to community and political matters (76.1\%); professional purposes and job findings (93.9\%); and connecting to family, friends and like-minded people $(99.0 \%)$.

\subsection{Attitude and Opinion towards Social Media}

Table 6. Attitude and opinion towards social media.

\begin{tabular}{|c|c|c|c|c|c|}
\hline Items & $\mathbf{N}$ & Minimum & Maximum & Mean & Std. Deviation \\
\hline Lack of privacy when using social media & 197 & 1.00 & 5.00 & 4.2741 & 1.01820 \\
\hline Lack of control of content post on social media & 197 & 1.00 & 5.00 & 3.8122 & .96904 \\
\hline There can be cyber abuse and malicious behaviour & 197 & 1.00 & 5.00 & 3.8020 & 1.32726 \\
\hline Can be a destruction & 197 & 1.00 & 5.00 & 3.4365 & 1.66055 \\
\hline Exposure of inappropriate online content & 197 & 1.00 & 5.00 & 3.2843 & 1.47095 \\
\hline Face to face communication can be discouraged & 197 & 1.00 & 5.00 & 3.1675 & 1.58673 \\
\hline Aggregate mean* & 197 & 1.00 & 5.00 & 3.49 & 1.28 \\
\hline
\end{tabular}

Note: *Aggregate mean was computed by averaging subjects' responses to the 7 individualism scales.

Source: Field data [2014]

Table 6 presents the individual mean scores of respondents' attitude and opinions towards social media on a five point Likert scale. The aggregate mean score of 3.49 was recorded indicating most of the respondents were in agreement to the statements. However, with regards to the statement, 'Lack of trust of peer feedback', respondents were indifferent with a mean score of 2.6244 .

\section{Summary Discussions and Conclusions}

\subsection{Summary Discussions}

The study has sought to explore the familiarity and usage of social media technology among teachers in Ghana. This is very important giving the recent proliferation and dominance of social media technology in human communication. Therefore, the phenomenon intrinsically begs for further study into how teachers have embraced the social media tools in Ghana. The study revealed significant familiarity of social media among teachers in Ghana [See Figure 2]. The finding reinforced [7, 19, 6] assertion of the varied importance and acceptability of social media usage across the globe in recent times. Thus, teachers use social media in diverse ways including personal, professional developments and for classroom practice such as researching purposes, as a discussion forum, and to access online resources for academic work etc.

Several researches $[19,14,13]$ have reported on the use of social media in classroom/instructional practice as it is believed to foster collaboration and discussion between teachers and their students. However, the study revealed an interesting finding regarding the use of social media for classroom and instructional practice. Thus, majority (71.6\%) of teachers in Ghana do not use social media for classroom and instructional practice [See Figure 5].

However, teachers frequently spend more hours on social media sites sharing images and other types of posts with their peers and students most of the times [Figure 7]. They frequently shared information of all forms, access online resources, and do research online via social media sites such as blackboard, academia.edu, LinkedIn, Slideshare and YouTube etc. [Table 4]. This is in line with [19,4 ] findings that faculty members from over fifty U.S. colleges and universities and elsewhere used social media technologies such as blogs, wikis, Google docs, video conferencing, video games, or virtual worlds for varied reasons but majority of students and teachers do not use it for classroom practice. Moreover, they use social media as a means of getting news, for fun/entertainment, share opinion, and to connect to friends and relatives. [6, 20] have revealed similar findings regarding the study of WhatsApp and voice call: preference of Polytechnic students in Ghana, and the impact of WhatsApp on students' academic performance respectively where they revealed that social media is used for entertainment, share opinion and connect to friends etc..

In spite of the growing interest and usage among the teachers in Ghana, the teachers' attitudes and opinions are 
quite reserving: they perceived the media as lacking privacy protection, can be a distraction, exposure to inappropriate online contents, cyber bullying, lack of control [Table 6]. Similarly, [21, 23, 24, 25] have extensively reported on many factors that could be hindering the use of Web 2.0 technologies in diverse ways. When these factors are importantly understood, people will be able to utilise those technology and the individual teachers can apply it in both their personal and general development.

Despite the familiarity and diverse usage among the respondents, problems such as poor internet connectivity, limited infrastructure, cost, workload, and privacy issues etc. appear to be hampering its smooth growth and integration in education in Ghana [Figure 6]. It was significantly found that a majority $(56 \%)$ of the teachers [Figure 4] access social media sites through their smart phones other than PC, and fixed internet or even laptops. This coincides with [22] study in Israel where, $94 \%$ of high school students accessed social media on their phones.

\subsection{Conclusions}

This paper relied on responses from randomly selected teachers in Ghana regarding how they are generally utilising the social media technology in their everyday interactions and activities. This is particularly important area which has not been explored in Ghana especially following the upsurge of the social media usage. Therefore, the study aimed at adding to the extant literature in Ghana with respect to the technology. It was consequently revealed that the majority of the teachers are using the technology in diverse ways. Gone are the days, when the media was just about posting photos or letting friends know what they are doing. People have come to appreciate the essence of using the tools to enhance or empower themselves differently and significantly. Social media is now everywhere. People are using it in their buying decisions, to stay in touch with friends, for research, developing personal and professional relationships. Therefore, managers and educational institutions in Ghana need to harness the technology properly to propel their businesses and institutions into new heights so as to increase their presence in the global economy. The technology has now become a new tool for business evangelism or a catalyst for word of mouth advertisement.

The study also provides opportunity for further investigation. For instance, it will be relevant to further examine managers and social media in Ghana, and knowledge and attitude towards the applications of social media tools in Ghana.

\section{References}

[1] Salem, F. and Mourtada, R. [2011]. The role of social media in Arab women empowerment. Arab Social Media Report 1[3], Retrieved from http: www.ArabSocialMediaReport.com [September 12, 2014]

[2] Lachapelle, P. [2011]. The use of social networking in community development. CD Practice, No.17. Available at http:// www.msucommunitydevelopment.org/pubs/paul [Accessed on July 12, 2014]

[3] APDEQ and EDAC Conference [2010]. Social media for economic development: Canadian and international best practice. Intelegiar Retrieved from http://www.slideshare.net/intelegia/edac-conference2010[June 23, 2014]

[4] Chen, B. and Bryer, T. [2012]. Investigating instructional strategies for using social media in formal and informal learning. The International Review of Research in Open and Distance Learning, 13(1), 87-100.

[5] Lenhart, A. Purcell., K. Smith, A. and Zickuhr, K. [2010]. Social media and mobile internet use among teens and young adults. Pew Internet \& American Life Project, 1-37. http://www.socialcapitalgateway.org [Accessed on November $15,2014]$

[6] Yeboah, S. T., Horsu, E. N. and Abdulai, A. [2014]. Usage of WhatsApp and Voice Calls (Phone Call): Preference of Polytechnic Students in Ghana. Science Journal of Business and Management. 2 [4] pp. 103-108. doi: 10.11648/j.sjbm.20140204.11

[7] Safran, C. (2010). Social media in education: Application scenarios supporting communities in technology- enhanced learning. PhD thesis submitted to The Institute for Information Systems and Computer Media, Graz University of Technology.

[8] Moran, M., Seaman, J. and Tinti-Kane, H. [2011]. Teaching, learning, and sharing: how today's higher education faculty use social media. Pearson Learning Solutions, the Babson Survey Research Group, and Converseon. Available online at $\mathrm{http} / / \mathrm{www}$.pearsonlearningsolutions.com [Accessed on November 20, 2014]

[9] Kaplan, A. and Haenlein, M. [2010]. Users of the world, unite! The challenges and opportunities of social media. Business Horizons, 53(1), 59-68. Available online at http//www.sciencedirect.com

[10] Junco, R. and Mastrodicasa, J. [2007].Connecting to the net generation: What higher education professionals need to know about today's students. Washington, DC, NASPA.

[11] Junco, R. [August, 2014]. Engaging Students through Social Media: Evidence Based Practices for Use in Student Affairs. $1^{\text {st }}$ ed. San Francisco, CA: Wiley/Jossey-Bass

[12] Bryer, T. and Zavattaro, S. [2011]. Social media and public administration: Theoretical dimensions and introduction to symposium. Administrative Theory \& Praxis, 33[3], pp.325340.

[13] Lederer, K. [2012]. Pros and cons of social media in the classroom. Campus Technology, 25(5), pp.1-2. Retrieved from $\mathrm{http}: / /$ campustechnology.com/Articles/2012/01/19/Pros-andCons-of-Social-Media-in-the-Classroom [June, 2014]

[14] Turkle, S. [2014]. Preference for Online Social Interaction. Chronicle of Higher Education, 50(21), B26.

[15] Hussain, I. et al [2012]. Academic use of social media: practices and problems of university students. ICEM, IPDR [Vol.30], IACSIT Press, Singapore.

[16] Maeve, D. and Aaron S. [2013]. Social Media Update 2013. Pew Research Internet Project. Available online at http://www.pewinternet.org. [August 9, 2014] 
[17] Madden, M. [2014]. Public Perceptions of privacy and security in the post-snowden era. Pew Research internet Project. Available online at http://www.pewinternet.org/2014/11/12/public-privacyperceptions[January 20, 2015]

[18] Wood, E., Mueller, J., Willoughby, T., Specht, J. \&DeYoung, T. (2005). Teachers' Perceptions: barriers and supports to using technology in the classroom. Education, Communication \& Information, 5(2), 184-206.

[19] Hagan, T [2013]. The potential of online technologies and social media in 21 st century teacher professional development and practice: A mixed methods study exploring teachers' personal, professional development and/ or classroom use of online technologies in Ireland and the United States of America. Vol. [1]. Thesis submitted to the Dublin City University, Holland

[20] Yeboah, J. and Ewur, G. D. (2014). The impact of WhatsApp messenger usage on students' performance in tertiary institutions in Ghana. Journal of Education and Practice, 5(6): 222-1735.
[21] Cuban, L., Kirkpatrick, H., \& Peck, C. (2001). High Access and Low Use of Technologies in High School Classrooms: Explaining an Apparent Paradox. American Educational Research Journal, 38(4), 813-834.

[22] Dr. Beeri, I and Daniel, D. [2007]. 94 percent of high school students accessed social media on their phones during class. Phys.org. Available at http://phys.org/news/2012-12-percenthigh-school-students-accessed.html

[23] Guy, R. [2012]. The use of social media for academic practice: A review of literature. Kentucky Journal of Higher Education, Policy and Practice 1[2]. Available online at http://uknowledge.uky.edu [December 15, 2014]

[24] Atkins et al. (2010). Transforming American Education: Learning Powered by Technology. from Available online at http:/www.ed.gov/sites/default/files/NETP-2010-finalreport.pdf [Retrieved, September, 2014]

[25] Lei, J. (2009). Digital natives as pre-service teachers: What technology preparation is needed? Journal of Computing in Teacher Education, 25(3) 